\title{
Synthesis and glycosidase inhibitory activity of new hexa-substituted C8-glycomimetics
}

\author{
Olivia Andriuzzi ${ }^{1}$, Christine Gravier-Pelletier ${ }^{* 1}$, Gildas Bertho ${ }^{1}$, \\ Thierry Prangé ${ }^{2}$ and Yves Le Merrer ${ }^{* 1}$
}

\section{Full Research Paper}

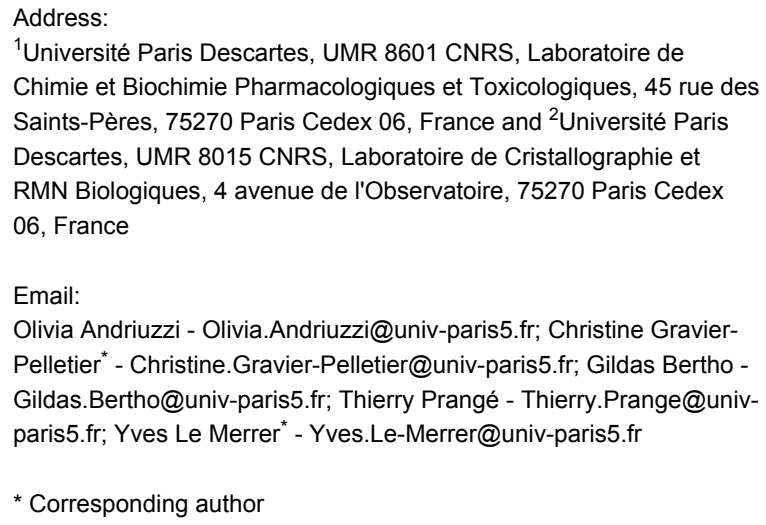

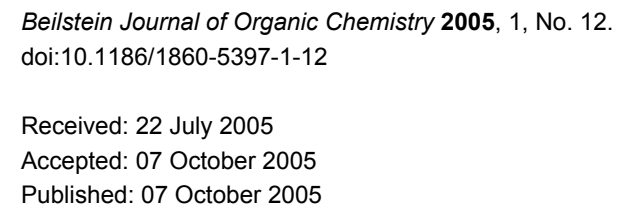


from that realized in glycomimetics such as valiolamine, voglibose and valienamine. Nevertheless, the synthetic strategy described here is efficient and general, and could be extended to increase the diversity of the glycosidase inhibitors obtained since this diversity is introduced in an ultimate step of the synthesis.

\section{Introduction}

There is a considerable interest in the design of molecules able to mimic carbohydrates which play critical roles in various biological events such as for example, cell-cell recognition and adhesion, cell growth and differentiation.[1-9] In this context, the goal is to obtain new compounds with improved efficacy, stability and specificity. Thus, a change from an aldopyranoside to a 1-deoxy-iminosugar (Figure 1) decreases the vulnerability of the resulting glycomimetic towards glycosidases, while the core structure and essential network of hydroxyl functionalities for enzyme recognition are retained. An important example is the 1-deoxynojirimycin (DNJ) family, for which DNJ itself is a competitive inhibitor of $\alpha$-D-glucosidase $\left(K_{\mathrm{i}}=8-25 \mu \mathrm{M}\right)$,[10] while its derivatives miglustat $\left(N-n \mathrm{Bu} \mathrm{DNJ}\right.$, Zavesa $\left.{ }^{\circledR}\right)$ and miglitol ( $N$-hydroxethyl DNJ, Glyset ${ }^{\circledR}$ or Diastabol ${ }^{\circledR}$ ) have already found therapeutic applications in Gaucher's disease [11] and type 2 (non-insulinodependant mellitus) diabetes, $[12,13]$ respectively. In the past decade, works have been targeted to carbasugars originally consisting of six-membered cyclitols, related to valiolamine, [14] voglibose, [15] valienamine, [16] and acarbose. [17] The last two compounds, marketed as Basen ${ }^{\circledR}$ and Glucor ${ }^{\circledR}$ or Precose ${ }^{\circledR}$, respectively, are also actually used in the treatment of type 2 diabetes. All these compounds can have their amino moiety protonated, and the corresponding ammonium ions mimick the charge of the presumed transition states or intermediates of the enzymatic glycoside hydrolyses [18].

More recently, attention has been increasingly accorded to seven- and eight-membered ring systems [19-30] in order to study the effect of the enhanced flexibility and of the new spatial distribution displayed by these structures on their adaptability in the active site of the enzyme.

As part of a program directed to the synthesis of potential glycosidases inhibitors, $[31,32]$ we focused on the access to new eight-membered carbasugars (Figure 2, $\mathrm{A}=\mathrm{OH}$ ) and related aminocyclitols $(\mathrm{A}=\mathrm{NHR})$ from $\mathrm{C}_{2}$-symmetrical L-ido- or D-manno- cyclooctene, easily available by ring closing metathesis of 1,9-diene derived from L-ido- or D-manno-bisepoxide [33]. Thus, synthetic potentialities of the newly created cyclic double bond were explored to reach hexa-substituted C8-glycomimetics.

\section{Results and discussion}

From the $\mathrm{C}_{2}$-symmetrical L-ido- or D-manno- cyclooctene, $\mathbf{1}$ or $\mathbf{2}$, to obtain the $\mathrm{C} 8$ hexa-substitued carbasugars a straight-<smiles>OCC1OC(O)C(O)C(O)C1O</smiles>

Sugar<smiles>OCC1NCCC(O)C1O</smiles>

DNJ : $\mathrm{R}=\mathrm{H}$

Miglustat: $\mathrm{R}=n \mathrm{Bu}$ Miglitol : $\mathrm{R}=\mathrm{CH}_{2} \mathrm{CH}_{2} \mathrm{OH}$<smiles>OCC1CC(N=P)C(O)C(O)C1O</smiles>

Valiolamine : $\mathrm{R}=\mathrm{H}$

Voglibose : $\mathrm{R}=\mathrm{CH}\left(\mathrm{CH}_{2} \mathrm{OH}\right)_{2}$

\section{$\mathrm{H}$}

Figure 1: Sugars, iminosugars and carbasugars.<smiles>OC1CC(O)C(O)C(O)CC1O</smiles>

$\mathrm{A}=\mathrm{OH}, \mathrm{NH}_{2}, \mathrm{NHR}$<smiles></smiles>

$1:$ L-ido

2 : D-manno

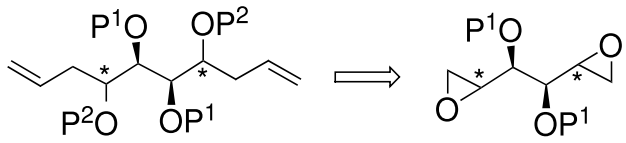

D-manno or L-ido 


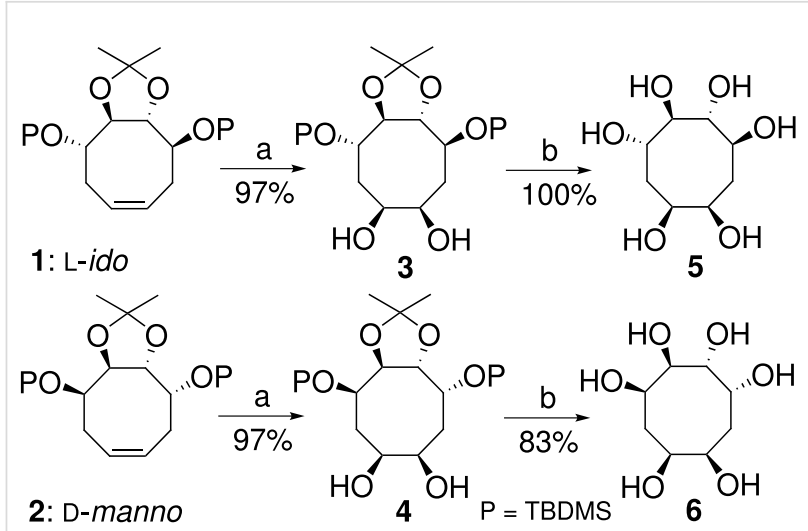

Scheme 1: Reagents and conditions: (a) $\mathrm{OsO}_{4}, \mathrm{NMO}, t \mathrm{BuOH}, \mathrm{rt}$; (b) TFA, $\mathrm{H}_{2} \mathrm{O}$, rt.

foward approach seemed to be a dihydroxylation, whereas to obtain the corresponding aminocyclitols it could be an epoxidation followed by the nucleophilic opening of the epoxide moiety by a primary amine or another nitrogen nucleophile. Accordingly (Scheme 1), treatment of the fully $O$-protected L-ido-cyclooctene 1 with a $5 \mathrm{~mol} \%$ aqueous solution of osmium(IV) tetroxide [34] in acetone in the presence of $\mathrm{N}$-methylmorpholine oxide and tert-butanol cleanly led to the expected cis-diol 3 in $97 \%$ yield. In analogous manner, the D-manno-cyclooctene 2 gave the corresponding cis-diol $\mathbf{4}$ in 97\% yield. In each case, the cis-diol $\mathbf{3}$ or $\mathbf{4}$ has been isolated as a single stereoisomer because of the $\mathrm{C}_{2}$-axis of symmetry displayed by the L-ido or D-manno-cyclooctenes $\mathbf{1}$ and $\mathbf{2}$. Then, simultaneous acidic hydrolysis of all the $O$-protective groups of $\mathbf{3}$ and $\mathbf{4}$ furnished the C8 hexa-substitued carbasugars $\mathbf{5}$ and $\mathbf{6}$ (80 to $97 \%$ overall yield for the two steps).

Now, to reach the corresponding aminocyclitols, we turned to the epoxidation [35] of the cyclooctenes 1 and $\mathbf{2}$ (Scheme 2)

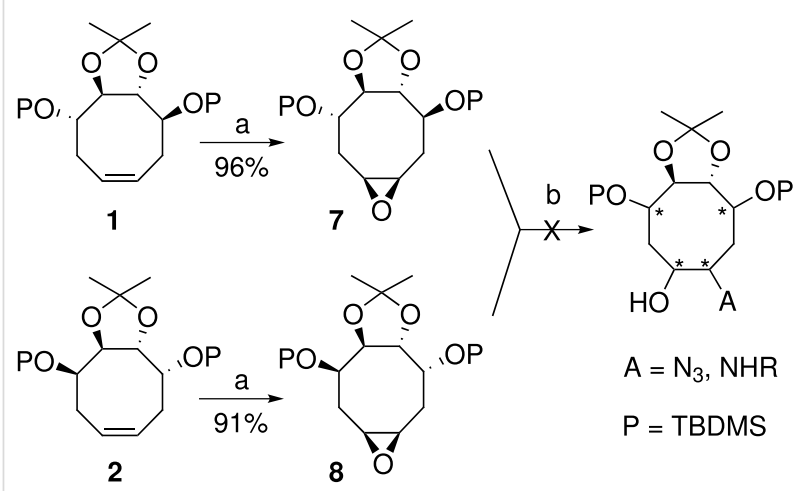

Scheme 2: Reagents and conditions: (a) $m \mathrm{CPBA}, \mathrm{CH}_{2} \mathrm{Cl}_{2}, \mathrm{NaHCO}_{3}$ rt; (b) see text.
Thus, treatment of $\mathbf{1}$ and $\mathbf{2}$ with meta-chloroperbenzoic acid in the presence of sodium hydrogen carbonate afforded the epoxides 7 and 8 in $91-96 \%$ yield. As precedently, because of the $\mathrm{C}_{2}$-axis of symmetry displayed by the L-ido or D-mannocyclooctenes $\mathbf{1}$ and $\mathbf{2}$ the cis-epoxide $\mathbf{7}$ or $\mathbf{8}$ has been isolated as a single stereoisomer. However, all attempts to open the epoxide ring involving various nucleophiles, sodium azide, benzylamine, $n$-butylamine, or serinol in different experimental conditions, protic or aprotic solvent, presence or absence of a Lewis acid catalyst such as ytterbium triflate, revealed unsuccessful, only leading to recover the starting material.

To overcome this difficulty, we turned to a more electrophilic sulfate moiety [36] (Scheme 3). Thus, treatment of the cis-diols $\mathbf{3}$ and $\mathbf{4}$ with thionyl chloride in the presence of triethylamine followed by subsequent oxidation with sodium periodate in the presence of ruthenium trichloride gave the cyclic sulfates 9 and 10 in $80-100 \%$ yield. Nucleophilic opening of these sulfates by sodium azide in DMF at $80^{\circ} \mathrm{C}$, [37] followed by acidic hydrolysis of the resulting acyclic sulfate ester cleanly afforded the corresponding azido-alcohols $\mathbf{1 1}$ and $\mathbf{1 2}$, isolated as single stereoisomers in excellent yield (95-98\%). No other isomer of 11 or 12 was detected by NMR analysis, indicating that the ring-opening reaction is highly regioselective and results in the anti addition of the azido group on the opposite side of the bulky TBDMS group in $\beta$-position. However, it has to be pointed out that more hindered nucleophiles, such as primary amines, revealed unable to open the cyclic sulfate $\mathbf{9}$ or $\mathbf{1 0}$.

The absolute configurations of $\mathbf{1 1}$ and $\mathbf{1 2}$ were established by NMR studies. ${ }^{1} \mathrm{H}$ signals were assigned (Table 1) using 2D-COSY and 2D-TOCSY experiments starting from hydroxyl group at $\mathrm{C} 8$-position.

The determination of all the coupling constants and particularly of the ${ }^{3} J_{1,8}$ was not possible by homodecoupling experiments. Thus, numerical simulation was used for an in depth study of the complex coupling patterns to set the parameters in complete analogy with regard to the experimental spectra. These ${ }^{3} J_{1 \mathrm{H}, 1 \mathrm{H}}$ coupling constants, determined by simulation (Figure 3) of 1D spectra with NMR-SIM started from XWIN-NMR software (Bruker), are gathered in Table 1. These values allowed us to restrain the number of conformations for the eight-membered ring. For example, in compound 11, the large ${ }^{3} J_{1 \mathrm{H}, 1 \mathrm{H}}$ coupling constants found between $\mathrm{H} 1$ and $\mathrm{H} 8, \mathrm{H} 1$ and $\mathrm{H} 2$ (proR), $\mathrm{H} 8$ and $\mathrm{H} 7$ (proR), $\mathrm{H} 4$ and $\mathrm{H} 5$, are in agreement with protons in a pseudo-axial position. On the other hand, the small ${ }^{3} J_{1 \mathrm{H}, 1 \mathrm{H}}$ coupling constants found between $\mathrm{H} 1$ and $\mathrm{H} 2$ (proS), $\mathrm{H} 8$ and $\mathrm{H} 7$ (proS) indicate a pseudo-equatorial position of protons $\mathrm{H} 2$ (proS) and $\mathrm{H} 7$ (proS). NOE measurements and finally Molecular Dynamic calculations using Insight II software 


\begin{tabular}{|c|c|c|}
\hline Proton & $\delta^{1} \mathrm{H}(\mathrm{ppm})$ & $2 J,{ }^{3} J(H z)$ \\
\hline 1 & 3.73 & $\begin{array}{l}3 J_{1-2 a}=2.2 \\
3 J_{1-2 b}=9.0 \\
{ }^{3} J_{1-8}=9.5\end{array}$ \\
\hline $2 \mathrm{a}(p r o S)$ & 2.06 & $\begin{array}{l}2 J_{2 a-2 b}=-15.4 \\
3 J_{2 a-3}=6.5\end{array}$ \\
\hline 2b (proR) & 1.90 & ${ }^{3} J_{2 \mathrm{~b}-3}=1.5$ \\
\hline 3 & 4.04 & ${ }^{3} J_{3-4}=4.2$ \\
\hline 4 & 3.50 & ${ }^{3} J_{4-5}=9.5$ \\
\hline 5 & 3.59 & ${ }^{3} J_{5-6}=6.3$ \\
\hline 6 & 3.94 & $\begin{array}{l}3 J_{6-7 a}=1.8 \\
3 J_{6-7 b}=5.5\end{array}$ \\
\hline 7a (proR) & 2.06 & $\begin{array}{l}2 J_{7 \mathrm{a}-7 \mathrm{~b}}=-15.4 \\
{ }^{3} J_{7 \mathrm{a}-8}=8.8\end{array}$ \\
\hline $7 \mathrm{~b}(p r o s)$ & 1.95 & ${ }^{3} J_{7 \mathrm{~b}-8}=1.5$ \\
\hline 8 & 3.73 & \\
\hline $8-\mathrm{OH}$ & 2.39 & \\
\hline
\end{tabular}

(Biosym Technologies, San Diego, CA) allowed to deduce the structure of 11 (Figure 4). Prochiral H2 (proS) and H7 (proS) protons displayed strong NOEs with the TBDMS groups, respectively in positions 3 and 6 , indicating they are pointing away from the $\mathrm{C} 8$ ring in a pseudo-equatorial position. Hence, the protons $\mathrm{H} 7$ (proR), H6, H4 are close together and represent
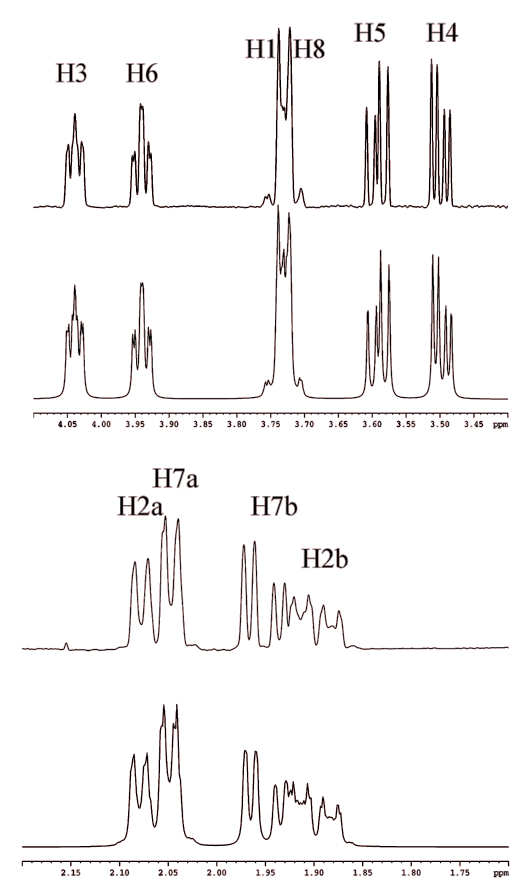

Figure 3: 1D proton NMR spectra of the C8 ring in compound 11 (upper) and the simulated signals (down) on the basis of the chemical shifts and coupling constants summarized in Table 1.<smiles></smiles><smiles>CC[C@H](C)OC1CC(O)C(N)CC(O)C(O)C1O</smiles>

Scheme 3: Reagents and conditions: (a) i: $\mathrm{SOCl}_{2}, \mathrm{Et}_{3} \mathrm{~N}_{1} \mathrm{CH}_{2} \mathrm{Cl}_{2}, 0^{\circ} \mathrm{C}$; ii : $\mathrm{RuCl}_{3}, \mathrm{NalO}_{4}, \mathrm{CCl}_{4}, \mathrm{CH}_{3} \mathrm{CN}, 0^{\circ} \mathrm{C}$ to rt; (b) $\mathrm{NaN}_{3}, \mathrm{DMF}, 80^{\circ} \mathrm{C}$; (c) $\mathrm{H}_{2}, \mathrm{Pd}$ black, EtOAc; (d) i: TFA, $\mathrm{H}_{2} \mathrm{O}$, rt; ii: Dowex-50WX8 $\mathrm{H}^{+}$resin, $1 \% \mathrm{NH}_{4} \mathrm{OH}$; (e) Ti(OiPr) $)_{4}, \mathrm{OC}\left(\mathrm{CH}_{2} \mathrm{O}\right)_{2} \mathrm{CMe}_{2}, \mathrm{CH}_{2} \mathrm{Cl}_{2}$ then $\mathrm{NaBH}_{3} \mathrm{CN}$, EtOH. 


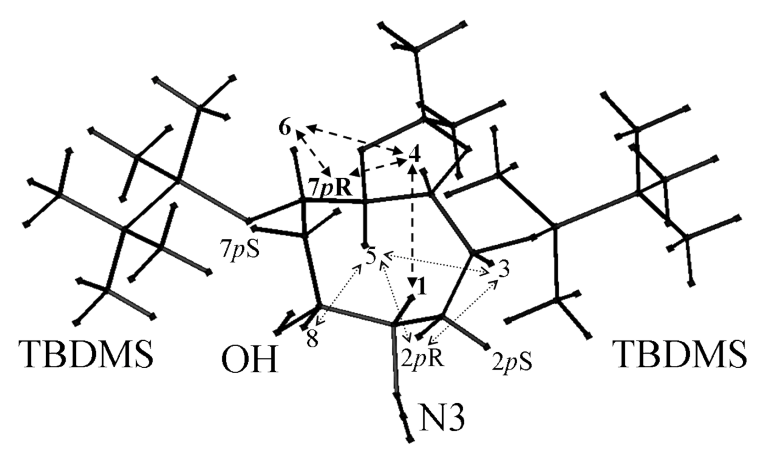

Figure 4: Schematic representation of the NOEs (indicated with arrows) found to deduce the structure of 11. Bold arrows show the NOEs found between the protons (in bold) of the upper face of the C8 ring. Prochiral ${ }^{1} \mathrm{H}$ are labelled $p \mathrm{R}$ or $p \mathrm{~S}$.

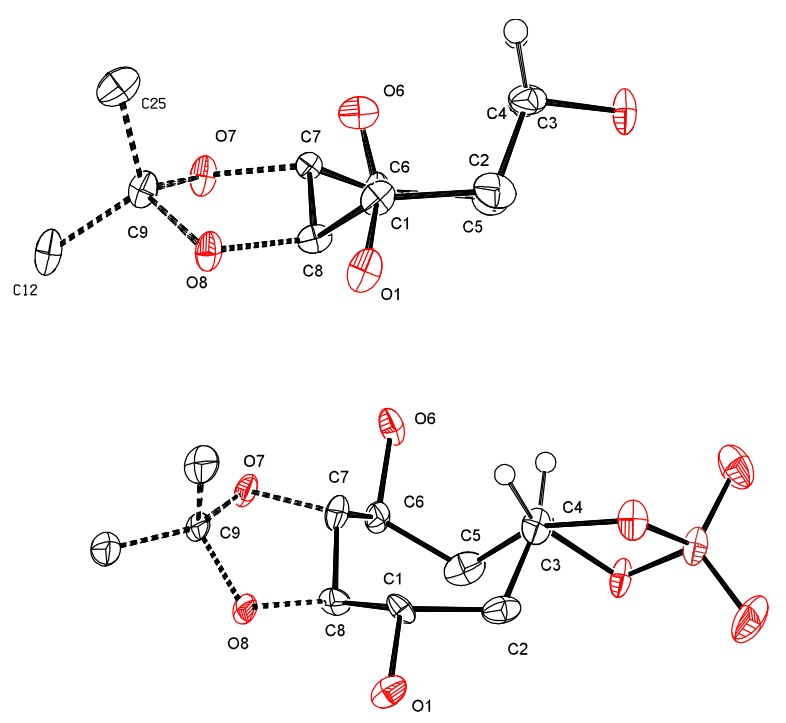

Figure 5: X-ray structure of epoxide 7 (upper) and sulfate $\mathbf{9}$ (down) solved using SHELXS and anisotropically refined using SHELXL programs [38].

one face (upper) of the $\mathrm{C} 8$ ring, while $\mathrm{H} 2$ (proR), H5, H3 represent the other face. Then, in compound 11, the strong NOEs $\mathrm{H} 1-\mathrm{H} 4$ and $\mathrm{H} 8-\mathrm{H} 5$ indicate that $\mathrm{H} 1$ and $\mathrm{H} 8$ are in opposite side in an anti configuration with pseudo-axial positions. A similar approach was applied for the structural determination of $\mathbf{1 2}$

The low reactivity of the epoxide function of 7 could be explained by the steric hindrance of the tert-butyldimethylsilyloxy groups in $\beta$-positions as confirmed by the X-ray crystallography (Figure 5). Furthermore, it seems that the C8-carbacycle of the tricyclic system [5-8-3] adopts a twist-boat-chair conformation. Whereas that of the sulfate 9, which crystallizes as a dimer, constituted by a tricyclic system [5-8-5] adopts a more flexible boat-chair conformation, thus allowing its opening by a linear nucleophile (azide anion), but not by a more hindered nucleophile (primary amine).

With the key enantiomerically pure azido-alcohol $\mathbf{1 1}$ and $\mathbf{1 2}$ in hands, we next turned to the obtention of $\mathrm{C} 8$-aminocyclitols. Thus, reduction of the azido group of $\mathbf{1 1}$ by dihydrogen in the presence of palladium black in ethyl acetate (Scheme 3) afforded the amino-alcohol $\mathbf{1 3}$ which could be submitted to acidic hydrolysis of the $O$-protective groups to give, after purification by ion-exchange chromatography, the targeted aminocyclitol 15 [20] (95\% overall yield from 11). Alternatively, to obtain an analog of voglibose, the amine function of $\mathbf{1 3}$ could be alkylated via a reductive amination [39] with a dihydroxyacetone derivative. Thus, treatment of the amine $\mathbf{1 3}$ by the commercially available 2,2-dimethyl-1,3-dioxan-5-one in the presence of titanium(IV) tetra-isopropoxide followed by the cyanoborohydride reduction of the imine intermediate gave the expected $N$-alkylated aminocyclitol 17 (46\% overall yield from 11). Then, simultaneous acidic hydrolysis of all protective groups led to the $\mathrm{C} 8$-voglibose mimetic $\mathbf{1 9}$ after purification by ion-exchange chromatography. The same sequence of reactions was uneventfully applied to the azido-alcohol $\mathbf{1 2}$ to afford the aminocyclitols 16 and $\mathbf{2 0 .}$

The new C8-carbasugars 5 and 6 and C8-aminocyclitols 15, 16, 19 and 20 have been assayed for their inhibitory activity towards 24 commercially available glycosidases [40,41]. They did not inhibit the following enzymes at $1 \mathrm{mM}$ concentration and optimal $\mathrm{pH}: \alpha$-D-glucosidases (maltase) from yeast and rice, $\beta$-D-glucosidase from caldocellum saccharolyticum, $\alpha$-Lfucosidases from bovine epididymis and human placenta, $\alpha$-Dgalactosidases from coffee beans and Escherichia coli, $\beta$-Dgalactosidases from Escherichia coli, bovine liver, Aspergillus niger and Aspergillus orizae, $\alpha-N$-acetylgalactosaminidase from chicken liver, $\beta$ - $N$-acetylglucosaminidases from Jack bean, bovine epididymis $\mathrm{A}$ and bovine epididymis $\mathrm{B}, \alpha-\mathrm{D}-$ mannosidase from almonds, $\beta$-D-mannosidase from Helix pomatia, and $\beta$-xylosidase from Aspergillus niger. For other enzymes: $\alpha$-D-glucosidase from Bacillus stearothermophilus, amyloglucosidase from Aspergillus niger and Rhizopus mold, $\beta$-D-glucosidase from almonds, $\alpha$-L-fucosidase from bovine kidney, and $\alpha$-D-mannosidase from Jack beans the results are shown in Table 2. Each of these new compounds revealed weak inhibitor of the tested enzymes with a percentage of inhibition not over than $30 \%$. These results show that the enhanced flexibility displayed by $\mathrm{C} 8$-glycomimetics does not seem to be correlated with an increase in observed activity. Thus, for example we had previously shown that the corresponding 


\begin{tabular}{|c|c|c|c|c|c|c|}
\hline Enzyme $^{a}$ & 5 & 6 & 15 & 16 & 19 & 20 \\
\hline \multicolumn{7}{|l|}{ a-D-Glucosidase } \\
\hline - Aspergillus niger & n.i. ${ }^{b}$ & n.i.b & $28 \%$ & n.i.b & $27 \%$ & $29 \%$ \\
\hline - Rhizopus mold & $20 \%$ & $21 \%$ & $23 \%$ & $20 \%$ & $28 \%$ & $27 \%$ \\
\hline - Bac. stearotherm. ${ }^{b}$ & $9 \%$ & n.i. ${ }^{b}$ & n.i. ${ }^{b}$ & $5 \%$ & n.i. ${ }^{b}$ & $6 \%$ \\
\hline$\beta$-D-Glucosidase & n.i. ${ }^{b}$ & n.i. ${ }^{b}$ & $7 \%$ & $11 \%$ & $6 \%$ & $19 \%$ \\
\hline a-D-Mannosidase & $5 \%$ & n.i. ${ }^{b}$ & $16 \%$ & $8 \%$ & $10 \%$ & $8 \%$ \\
\hline$\alpha-L-F u c o s i d a s e$ & $14 \%$ & $13 \%$ & n.i. ${ }^{b}$ & n.i. $b$ & n.i. ${ }^{b}$ & n.i. ${ }^{b}$ \\
\hline
\end{tabular}

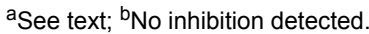

C7-voglibose mimic exhibited interesting activity towards amyloglucosidases from Aspergillus niger and Rhizopus mold (35 and $18 \mu \mathrm{M}$ respectively, unpublished results). Furthermore, even if data concerning biological activity of C8-glycomimetics are seldom, the reported activities are often weak [24-30].

In summary, utilizing the readily available polyhydroxylated L-ido or D-manno-cyclooctenes, coming from ring closing metathesis of C2-symmetrical 1,9-dienes, we have accomplished the synthesis of a range of new hexa-substituted C8-glycomimetics in enantiopure form. Transformation of the cyclic double bond involved syn-dihydroxylation, then introduction of an azido group by opening of a cyclic sulfate followed by reduction and eventual alkylation of the resulting amine.

According to this strategy and to the nature of the ketones involved in the final reductive amination, various aminocyclitols could be synthesized. Thus, in this study two carbasugars and four aminocyclitols were obtained. Biological evaluation of these compounds towards 24 commercially available glycosidases have been carried out. For these C8-glycomimetics, weak activities were observed, which can probably be explained by a too high conformational flexibility of such structures.

\section{Experimental}

See Supporting Information File 1.

\section{Supporting Information}

\section{Supporting Information File 1}

Additional information.

[http://www.beilstein-journals.org/bjoc/content/

supplementary/1860-5397-1-12-S1.doc]

\section{Acknowledgments}

We gratefully acknowledge Pr P. Vogel and Ms C. Schuetz, Ecole Polytechnique Fédérale de Lausanne, Switzerland, for their expertise in biological tests.

\section{References}

1. Drinnan, N. B.; Vari, F. Mini-Rev. Med. Chem. 2003, 3, 633-649. doi:10.2174/1389557033487737

2. Peri, F. Mini-Rev. Med. Chem. 2003, 3, 651-658. doi:10.2174/ 1389557033487700

3. Fugedi, P. Mini-Rev. Med. Chem. 2003, 3, 659-667. doi:10.2174/ 1389557033487755

4. Houston, T. A.; Blanchfield, J. T. Mini-Rev. Med. Chem. 2003, 3, 669-678. doi:10.2174/1389557033487827

5. Chhabra, S. R.; Rahim, A. S.; Kellam, B. Mini-Rev. Med. Chem. 2003, 3, 679-687. doi:10.2174/1389557033487791

6. Lowary, T. L. Mini-Rev. Med. Chem. 2003, 3, 689-702. doi:10.2174/ 1389557033487683

7. Hurtley, S.; Service, R.; Szuromi, P. Science 2001, 291, 2337-2378. doi:10.1126/science.291.5512.2337

8. Sears, P.; Wong, C. H. Angew. Chem., Int. Ed. 1999, 38, 2300-2324. doi:10.1002/(SICI)1521-3773(19990816)38:16<2300::AIDANIE2300>3.3.CO;2-Y

9. Chapleur, Y. Carbohydrate Mimics: Concepts and Methods; WileyVCH: Weinheim, 1997.

10. Winchester, B.; Fleet, G. W. J. Glycobiology 1992, 2, 199-210. doi:10.1093/glycob/2.3.199

11. Platt, F. M.; Niese, G. R.; Reinkensmeir, G.; Townsend, M. J.; Perry, V. H.; Proia, R. L.; Winchester, B.; Dwek, R. A.; Buters, T. D. Science 1997, 276, 428-431. doi:10.1126/science.276.5311.428

12. Mooradian, A. D.; Thuman, J. E. Drugs 1999, 57, 19-29. doi:10.2165/ 00003495-199957010-00003

13. Scott, L. J.; Spencer, C. M. Drugs 2000, 59, 521-549. doi:10.2165/ 00003495-200059030-00012

14. Kameda, Y.; Asano, N.; Yoshikawa, M.; Takeuchi, M.; Yamaguchi, T.; Matsui, K.; Horii, S.; Fukase, H. J. Antibiot. 1984, 37, 1301-1307.

15. Horii, S.; Fukase, H.; Matsuo, T.; Kameda, Y.; Asano, N.; Matsui, K. J. Med. Chem. 1986, 29, 1038-1046. doi:10.1021/jm00156a023

16. Chen, X.; Fan, Y.; Zheng, Y.; Chen, Y. Chem. Rev. 2003, 103 , 1955-1977. doi:10.1021/cr0102260

17. Truscheit, E.; Frommer, W.; Junge, B.; Müller, L.; Schmidt, D. D.; Wingender, W. Angew. Chem., Int. Ed. Engl. 1981, 20, 744-761. doi:10.1002/anie.198107441

18. Lillelund, V. H.; Jensen, H. H.; Liang, X.; Bols, M. Chem. Rev. 2002, 102, 515-533. doi:10.1021/cr000433k 
19. Gravier-Pelletier, C.; Maton, W.; Dintinger, T.; Tellier, C.; Le Merrer, Y. Tetrahedron 2003, 59, 8705-8720. doi:10.1016/j.tet.2003.09.049

20. Marco-Contelles, J.; de Opazo, E. J. Org. Chem. 2002, 67, 3705-3717. doi:10.1021/jo0111107

21. Marco-Contelles, J.; de Opazo, E. J. Org. Chem. 2002, 65, 5416-5419. doi:10.1021/jo000110o

22. Marco-Contelles, J.; de Opazo, E. Tetrahedron Lett. 1999, 40, 4445-4448. doi:10.1016/S0040-4039(99)00769-8

23. Johnson, C. R. Acc. Chem. Res. 1998, 31, 333-341. doi:10.1021/ $\operatorname{ar} 970013 q$

24. Mehta, G.; Pallavi, K. Chem. Commun. 2002, 2828-2829. doi:10.1039/ b208918a

25. Wang, W.; Zhang, Y.; Zhou, H.; Blériot, Y.; Sinaÿ, P. Eur. J. Org. Chem. 2001, 1053-1059. doi:10.1002/1099-0690(200103) 2001:6<1053::AID-EJOC1053>3.3.CO;2-J

26. van Hooft, P. A. V.; van der Marel, G. A.; van Boeckel, C. A. A.; van Boom, J. H. Tetrahedron Lett. 2001, 42, 1769-1772. doi:10.1016/ S0040-4039(00)02318-2

27. Boyer, F. D.; Hanna, I.; Nolan, S. P. J. Org. Chem. 2001, 66, 4094-4096. doi:10.1021/j00155761

28. Marco-Contelles, J.; de Opazo, E. Tetrahedron Lett. 2000, 41, 5341-5345. doi:10.1016/S0040-4039(00)00837-6

29. Wang, W.; Zhang, Y.; Sollogoub, M.; Sinaÿ, P. Angew. Chem., Int. Ed. 2000, 39, 2466-2467. doi:10.1002/1521-3773(20000717) 39:14<2466::AID-ANIE2466>3.0.CO;2-U

30. Armbruster, J.; Stelzer, F.; Landenberger, P.; Wieber, C.; Hunkler, D.; Keller, M.; Prinzbach, H. Tetrahedron Lett. 2000, 41, 5483-5487. doi:10.1016/S0040-4039(00)00905-9

31. Andriuzzi, O.; Gravier-Pelletier, C.; Vogel, P.; Le Merrer, Y. Tetrahedron 2005, 61, 7094-7104. doi:10.1016/j.tet.2005.05.066

32. McCort, I.; Sanière, M.; Le Merrer, Y. Tetrahedron 2003, 59, 2693-2700. doi:10.1016/S0040-4020(03)00257-6

33. Andriuzzi, O.; Gravier-Pelletier, C.; Le Merrer, Y. Tetrahedron Lett. 2004, 45, 8043-8046. doi:10.1016/j.tetlet.2004.08.172

34. Dougherty, J. M.; Probst, D. A.; Robinson, R. E.; Moore, J. D.; Klein, T. A.; Snelgrove, K. A.; Hanson, P. R. Tetrahedron 2000, 56, 9781-9790. doi:10.1016/S0040-4020(00)00885-1

35. Barett, S.; O'Brien, P.; Steffens, H. C.; Towers, T. D.; Voith, M. Tetrahedron 2000, 56, 9633-9640. doi:10.1016/S0040-4020(00)00911$\mathrm{X}$

36. Gao, Y.; Sharpless, K. B. J. Am. Chem. Soc. 1988, 110, 7538. doi:10.1021/ja00230a045

37. Moon Kim, B.; Sharpless, K. B. Tetrahedron Lett. 1989, 30, 655-659. doi:10.1016/S0040-4039(01)80274-4

38. SHELXL97. Program for the refinement of crystal structures; University of Göttingen: Germany, 1997.

39. Mattson, R. J.; Pham, K. M.; Leuck, D. J.; Cowen, K. A. J. Org. Chem. 1990, 55, 2552-2554. doi:10.1021/j000295a060

40. Saul, R.; Chambers, J. P.; Molyneux, R. J.; Elbein, A. D. Arch. Biochem. Biophys. 1983, 221, 593-597. doi:10.1016/0003-9861(83) 90181-9

41. Brandi, A.; Cicchi, S.; Codero, F. M.; Frignoli, B.; Goti, A.; Picasso, S.; Vogel, P. J. Org. Chem. 1995, 60, 6806-6812. doi:10.1021/ jo00126a033

\section{License and Terms}

This is an Open Access article under the terms of the Creative Commons Attribution License

(http://creativecommons.org/licenses/by/2.0), which permits unrestricted use, distribution, and reproduction in any medium, provided the original work is properly cited.

The license is subject to the Beilstein Journal of Organic Chemistry terms and conditions:

(http://www.beilstein-journals.org/bjoc)

The definitive version of this article is the electronic one which can be found at:

doi:10.1186/1860-5397-1-12 